\title{
Osmosis cultural en la Frontera. Arte en la frontera Nazari
}

\section{Pedro Galera Andreu}

Liniversidad de Gramala

A esta cita que nos hace la Dirección Provincial del Ministerio de Cultura de Melilla en torno al tema de la "Ciudad y la Frontera", aun cuando se organice desde y para el Norte de Africa, he querido contribuir analizando la permeabilidad cultural, artística en concreto, entre territorios limítrofes tomando como referencia la frontera nazarí en tanto en cuanto confrontación e influencia mutua de las culturas islámica y cristiana.

La Península lbérica, quizá como pocas regiones en el tiempo y en el espacio, pueda presumir de tal experiencia a lo largo de todo su Medievo, aunque fuera al final de la Baja Edad Media. quedando ya sólo el Reino de Granada de único bastión del poder musulmán, cuando media Andalucía fue protagonista de la "Frontera" por antonomasia. pues con ese término era denominada la amplia línea que separaba los dominios nazaríes de los de Castilla.

En esa Frontera, un reino y una ciudad. Jaén, por su cercanía a la ciudad de la Alhambra. vivió de forma intensa y muy particular el f́nómeno fronterizo. A Ella le prestó memorable atención el historiador Juan de Mata Carriazo en una serie de trabajos recogidos con el título gene- 
ral de En la Frontera de Granada (1). En la Introducción al volumen I de ese libro, Carriazo perfilaba con exactitud el papel de ese límite, que creo oportuno recordar: "A través de esa frontera - escribe- se han filtrado muchas influencias recíprocas, se han creado instituciones muy singulares, como el juez entre los cristianos y los moros y los fieles del rastro, han surgido géneros literarios muy valiosos, como los romances fronterizos y las novelas moriscas, se ha elaborado un nuevo arte de la guerra y una nueva arquitectura militar, y por encima de la incompatibilidad religiosa, se han producido fenómenos muy delicados y significativos de comprensión, tolerancia y cortesía" (2).

\section{JAEN DEL CONDPSTABLE}

Se basó don Juan de Mata para elaborar el trabajo arriba citado en una documentación existente en cl Ayuntamiento de Jaén que data de 1479: El Libro de Actas de ese año, que recoge puntuales noticias de la vida cotidiana entre pacífica y belicosa, de ambos lados de la frontera. Pero una década antes la ciudad de Jaén conoció a un personaje singular: prototipo de aquella caballería autumnal de la Edad Media, que encarnó perfectamente en su persona y en su entorno el espíritu de la "frontera", generador en gran medida de la figura del Señor y del Señorío, en cuanto institución, en la Andalucía bajo medieval, tal como afirma Ladero Quesada (3).

Aquel personaje era don Miguel Lucas de Iranzo, quien desde 1459 hasta su muerte violenta en 1473, fue Condestable de Enrique IV en Jaén y a cuya Crónica o Relación de los fechos del mui magnífico e mas virtuosos señor.. debemos una información preciosa sobre la vida cultural de una ciudad fronteriza. Esta obra, cuya edición de 1940 estuvo a cargo también del profesor Carriazo (4), es una pieza admirada no sólo por las noticias históricas (como tal quizá no sea del todo fiable, dado el carácter elegíaco que tiene) sino más bien por su interés antropológico y literario.

La pobre y pequeña ciudad que era Jaén, desvencijada a tenor de la suerte que corría desde que fuera conquistada en 1247 por Fernando III, donde los asaltos de los musulmanes menudearon a lo largo de los siglos XIII y XIV (en 1368 gran parte de ella fue incendiada en un ataque generalizado que afectó también a Ubeda y Baeza) adquiere ahora, pasada la mitad del siglo $\mathrm{XV}$, un esplendor inusitado al transformarse en una pequeña Corte a escala de la Corte Real por el empeño de don Miguel Lucas de 
Iranzo. El voluntarismo y: en consecuencia, el protagonismo del Condestable, entiendo que es un rasgo fundamental para definir este concepto de ciudad de frontera, configurada como enclave periférico que emula y a la vez mantiene una relación tensa con un centro al que sirve o defiende y al cual pretende tener siempre en deuda.

Una angustiosa carta de Iranzo al Papa Sixto IV pidiendo concesión de Indulgencias para quienes quisieran ir a guerrear a Jaén, una declaración de Cruzada en suma. define a mi modo de ver esta situación perfectamente: "Sabrá vuestra Santidad que doce años puede aver, poco mas o menos, que por serviçio de Dios, ensalçamiento de su Fe, defensión desta frontera, acordé no solamente desterrarme de la corte del rey mi señor y de los grandes favores que en ella tenia, mas venirme de asiento a bevir a esta çibdad, do tantos, tan grandes y continuos daños facian los moros, a que ningund capitan, sin grand pena y temor, la ossase tomar en cargo. $Y$ estava ya la gente tan acostumbrada a ser vençida y tan desamparada desfuerço de capitanes, que ya desesperavan de se poder defender y aquesta çibdad, perdida, perdiase quasi toda esta tierra; que sola ella es el escudo que defiende por esta parte lo mas del Andalucia" (5).

Destierro. heroísmo, se trocaban en la distancia en frenćtica actividad de gobierno, cuyo fin primordial era la afirmación del poder, de un poder que representaba a la Corona de Castilla. pero que ambiguamente se tiñe de "virtú" humanística prerenacentista en la persona de Iranzo, capaz de sustentar o auspiciar un poder señorial, a la larga. autónomo. En cualquier caso el resultado es un beneficio material indiscutible para la ciudad: Amplias reformas urbanísticas, tendentes a crear plazas y calles principales allanadas donde el caballo sea el protagonista indiscutible, pues tras este animal, emblemático de una clase social, se pretende propagar el desarrollo y afianzamiento de esa clase, la pequeña nobleza, apenas en ciernes. Justas; juegos de cañas y del anillo y cabalgadas con cualquier pretexto, forman parte del mayor espectáculo público que propina la máxima autoridad. La ciudad se ha convertido en gran medida en un espacio representativo.

En virtud de esa representatividad la Fiesta adquiere especial relevancia, de forma que el calendario anual se rige por medio de estos acontecimientos: Navidad, Reyes, la Candelaria, Carnaval, Jueves y Viernes Santo, primero de Mayo. Corpus Christi, San Juan, La Asunción (Feria), San Lucas, Todos los Santos, que afectan como puede observarse a todos y 
cada uno de los meses del año, y a las que habría que unir las celebradas con motivo de visitas ilustres y lo que puede resultar más significativo, los homenajes a sus vecinos y rivales, los alcaides de Cambil, avanzada nazarí a sólo 20 Kilómetros de Jaén.

La minuciosa descripción de las mismas en la Crónica nos permite comprobar algunos puntos de interés para después extraer algunas conclusiones:

A) Carácter u origen pagano de algunas de ellas.

B) Impregnaciones humanistas modernas.

C) Importancia del mimo y la representación teatral como símbolo general.

D) La paradoja de tratar de consolidar el poder en lo efímero de la Fiesta.

Aun cuando el contenido dominante de esas festividades es religioso, la puesta en escena, por el marcaro carácter urbano que persigue el Condestable, no puede evitar un alto grado de contaminación laica donde se dan la mano viejas tradiciones paganas y nuevas modas o costumbres al uso en Europa, sobre todo francesas e italianas. Así, con motivo del Carnaval, el día más importante de celebración era el martes (equivalente al "Mardi Gros" francés) con grotescos torneos de calabazas a cargo de los campesinos; se "corría la sortija" ante el Palacio y se comía y se bebía en justa correspondencia al homenajeado "Don Carnal". Pero era el 1 de mayo y el 24 de junio, San Juan, cuando el trasfondo pagano del culto solar con motivo del equinoccio de verano afloraba marcado por un tono humanista acorde con la Italia de Petrarca. En aquella ocasión, antes del amanecer, el propio don Miguel acompañado de su séquito emprendia una procesión, profana al río Guadalbullón, en las afueras de la ciudad, donde se coronaban con guirnaldas de flores para volver de nuevo a hacer su entrada en laén por las calles cubiertas también de flores, cañas y juncia. A continuación, como gran festejo, se celebraba un torneo o batalla entre moros y cristianos.

Para esta ocasión el Condestable vestía y montaba a la morisca, pasando en el combate simulado a desempeñar el papel del rey moro frente al Alguacil o autoridad municipal, que encarnaba el de líder cristiano. Obvio es decir que en este caso eran los moros vencedores. En otras ocasiones, cuando recibía al Alcaide de Cambil principalmente, los alardes militares con que lo obsequiaba eran en el más estricto sentido una brillan- 
te demostración de su fuerza bélica. O bien, al socaire del teatro, un dragón, animal simbólico muy arraigado en la tradición oral y literaria de Jaén (6). devoraba a los moriscos prólugos.

Lo importante a destacar en todo este impresionante despliegue festivo es cómo junto al peso de las costumbres occidentales, nuevas y antiguas, hay una presencia de lo islámico como constante referencia al "otro", próximo y vecino, que justifica en última instancia el papel del Condestable en Jaén y de la ciudad misma en cuanto que enclave de avanzadilla en la frontera. Sin embargo, no quisiera decir que la nota morisca signifique una mera máscara coyunturalmente empleada y desafecta para esta pequeña corte. Al contrario, su presencia en estos círculos de élite se reviste de todo lo complejo de la permeabilidad que opera entre dos culturas sometidas durante mucho tiempo a una vecindad cargada de tensión. Que el Condestable gustara de vestir a la morisca no puede extrañarnos cuando toda la casa de Trastamara desde tiempo atrás (recuérdese a Pedro I y el Alcázar de Sevilla) alardeaba de ese gusto. Otro detalle además a considerar podría ser la afición por las fieras exóticas: leones y osos que tenía en cotos en los alrededores de Jaén y de su mismo palacio, de similar forma a como los reyes nazaríes lo tenían en los montes que rodean la Alhambra.

\section{EL PALACIO DEL CONDESTABLE}

Pero donde mejor puede apreciarse el influjo islámico es en la arquitectura que se hace por esas fechas en Jaén, empezando por la propia mansión de Iranzo. Aunque sólo ha llegado parcialmente hasta nosotros. convertido desde el pasado siglo en Casino y posteriormente en cine, sabemos que su estructura es similar a la de las grandes casas musulmanas. organizada en torno a patios porticados a los que abrían salas cubiertas con alfarjes, a juzgar por una descripción de mediardos del siglo XIX hecha por el marqués de Pidal (7).

Hay que tener en cuenta las reformas sufridas por el palacio al pasar pronto, en el siglo XVI a manos del conde de Villardompardo, las mismas que continuaron en las dos centurias siguientes. Pese a ello es suficiente lo visto por el marqués de Pidal para asegurar esa filiación morisca, que para mayor precisión diremos mudéjar. Para empezar, al narrador le llama la atención lo anodino del exterior: "Modesta en demasía la portada que hoy tienen las casas del Condestable, nada ofrece a la vista que haga presentir el 


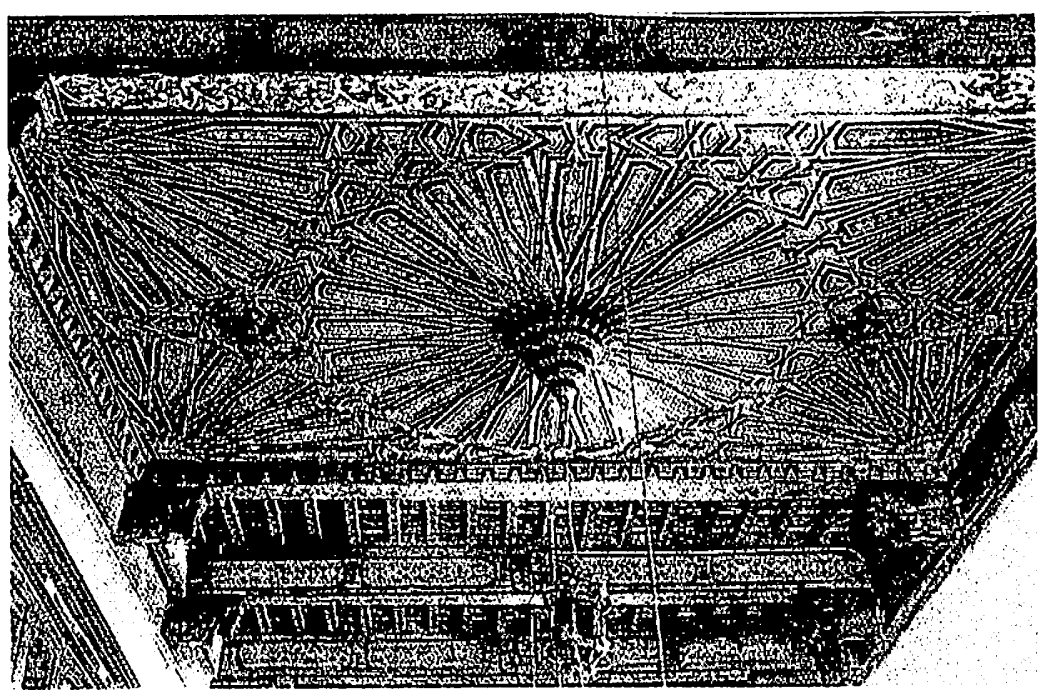

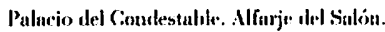

lujo y antigua magnificencia de su interior..." Lo que entendía debía ser fruto de modernas intervenciones, pero que sin embargo concuerda con el espíritu musulmán de ocultar hacia afuera el esplendor de adentro.

Mas al entrar en el primer zaguán —continúa- se presenta ya el espacioso patio u alfagia (...) y en el fondo del cual, a través de jazmines, rosales y otras plantas olorosas, se descubre un grandioso vestíbulo de cinco arcadas (...) del último periodo de la arquitectura ogival. Encima del pórtico se divisan algunas de las ventanas del piso principal (...) Sobre este piso segundo, $y$ el ángulo del lienzo que forma martillo con el que mira a la calle Maestra, se levanta una torre cuadrada, al través de cuyas espaciosas ventanas se descubre aún la rica techumbre morisca labrada de vistosa atauxía...

Si este último elemento nos recuerda a las esbeltas torres con miradores, visibles en la Alhambra, sobre todo la de las Damas en el Partal. pronto comprobamos que la decoración interior respondía a modelos palaciegos nazaríes. Así, "La puerta que da entrada a las habitaciones principa- 
les se parece bastante a algunas del Alcázar de Sevilla y Alhambra de Granada: consiste en decoración, que ocupa toda la altura de la pared, en una línea de siete lindísimas arcadas, colocadas sobre el arco de entrada, y cuyos huecos, según el gusto de la época, llenan varias claravoyas o trafloros de labor de yeso y ataurique. La ornamentación, sin embargo, es gótica, y a pesar de que algunas arcadas partidas en dos y sostenidas por una columnita tienen la apariencia de ajimez árabe. A este género pertenecen los adornos del alféizar o grueso del arco principal, y las de las dos fajas verticales que componen el rabá y la guarnecen por ambos lados. Vénse aún en la parte superior los pernios o goznes de las puertas de alerze que en lo antiguo hubo; los cuales, así como la piña colgante en el centro del techo, tienen la forma del racimo de bovedillas árabes, y están dorados y perfilados con bermellón". En este largo párrafo, pese a algunas incorrecciones de términos (alféizar por sofito o intradós, aunque quizá se quiere referir a las enjutas del arco) revela el carácter híbrido de estilo y materiales.

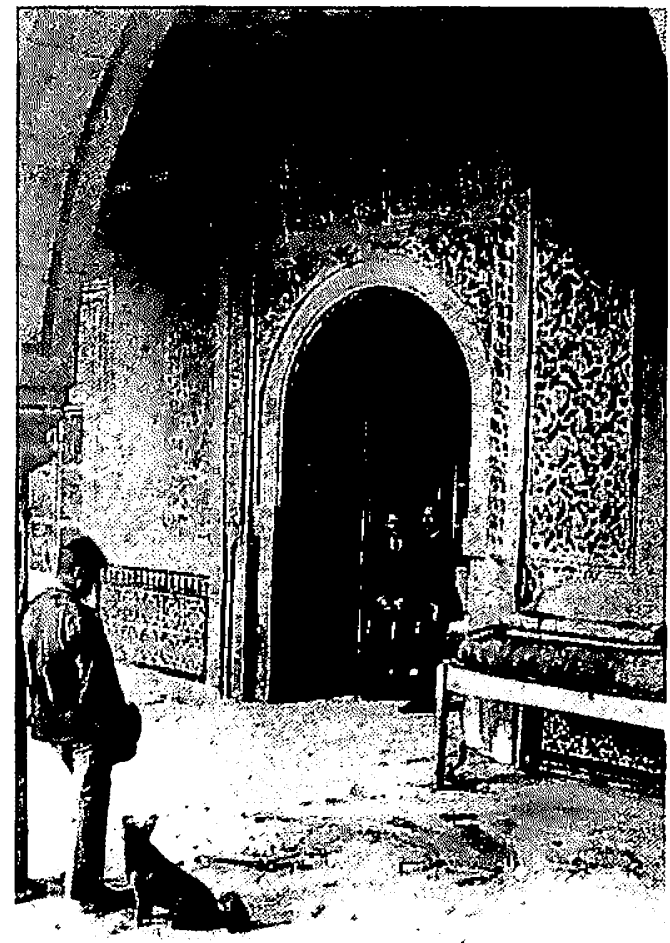

Antiguo Palatio del Combestable. Portudu drsapareciela (foto de fines del XIX) donde se entremezclan el gótico último o flamígero con el granadino nazarí, elaborado sin duda por manos mudéjares, dando origen a un abigarrado estilo ornamental en yesería. preferentemente, del que alguna foto antigua da testimonio fiel. Asimismo el resto de un arco perteneciente a una casa particular: conocido como el "Arco de la casa de la Virgen", hoy en el Museo Provincial de Jaén, permite hacernos una idea del desarrollo de dicha hibridez artística. Aquí también la 
floritura fluida del diseño gótico se transforma en rígidos esquemas geométricos que ocupan toda la superficic, de acuerdo a un concepto preciso de ordenación matemática de la superficie propio del arte islámico.

Actualmente sólo queda del viejo Palacio un gran salón, sin duda el principal por sus dimensiones, con su techumbre de alfarje "hecha toda de maderas finas - como la describe Pidal $-y$ sostenida por vigas o tirantes primorosamente perfilados y pintados de atauxía, así como los canes que en esta se apoyan". Ruedas de lacería con piña de mocárabes policromados ocupan la superficie lisa, visibles todavía de la mejor tradición granadina, que se dan la mano con los escudos de armas pintados de Lucas de Iranzo y su mujer, doña Guiomar Carrillo.

Cercano al palacio, aún se conserva la Capilla del Arco de San Lorenzo, que en su día fue la capilla del desaparecido Hospital de la Madre de Dios fundado por el hijo del Condestable, don Luis de Torres. Ocupa los bajos de un torreón aislado, único resto de la desaparecida iglesia de San Lorenzo a la que estaba unido por un arco gótico bajo el que discurre la calle Maestra Alta. Se accede a la capilla por una pequeña puerta ojival. pero en su interior la decoración es claramente de raigambre islámica con un zócalo de alicatado mudéjar formado por dibujos poligonales y cenefas de lacería, al igual que la mesa de altar donde dominan los típicos temas de ruedas de lazos originando estrellas de 24 puntas, tan abundantes en la Alhambra. Sobre el altar, nicho de yesería, igualmente de factura mudéjar, mezcla lo gótico con diseños de tradición musulmana.

En resumen, la arquitectura olicial se perfila como un producto mudéjar que revela la atracción por el arte del enemigo o de los grupos sociales ya francamente minoritarios como los muléjares mismos, en franca regresión desde la conquista cristiana de la Bética, según manifiestan los estudios demográficos de los medievalistas, en beneficio de los pobladores castellanos. Sin embargo, como contrapunto, el palacio e incluso algún escenario público se adornan con tapices y reposteros, que por su temática y denominación de "franceses", estarían en la órbita de los flamencos. De nuevo, la simbiosis entre el gusto internacional del "otono de la Edad Media", que no era otro que el gótico flamígero de cuño francés y centroeuropeo, idealista y naturalista a la vez, y el concepto artístico del mundo islámico representado básicamente por el arte nazarí, la simbiosis se convierte en cierta manera en metáfora de la misma situación política de la Frontera, amigable y belicosa a un tiempo. 


\section{ARTE CRISTIANO BN IA ALHAMBRA}

Por su parte, en el aparentemente hermético reino granadino, el arte cristiano llega al mismo corazón de la $A$ lhambra desde fines del siglo XIV con las pinturas sobre cuero que decoran tres estancias de la llamada Sala de la Justicia. Estas, todavía enigmáticas en muchos aspectos, representan una especie de Consejo o Tribunal de altos dignatarios interpretado por la mayor parte de los historiadores (9) como los retratos de los reves nazaries, y en las dos alcobas laterales sendas escenas caballerescas con tor-

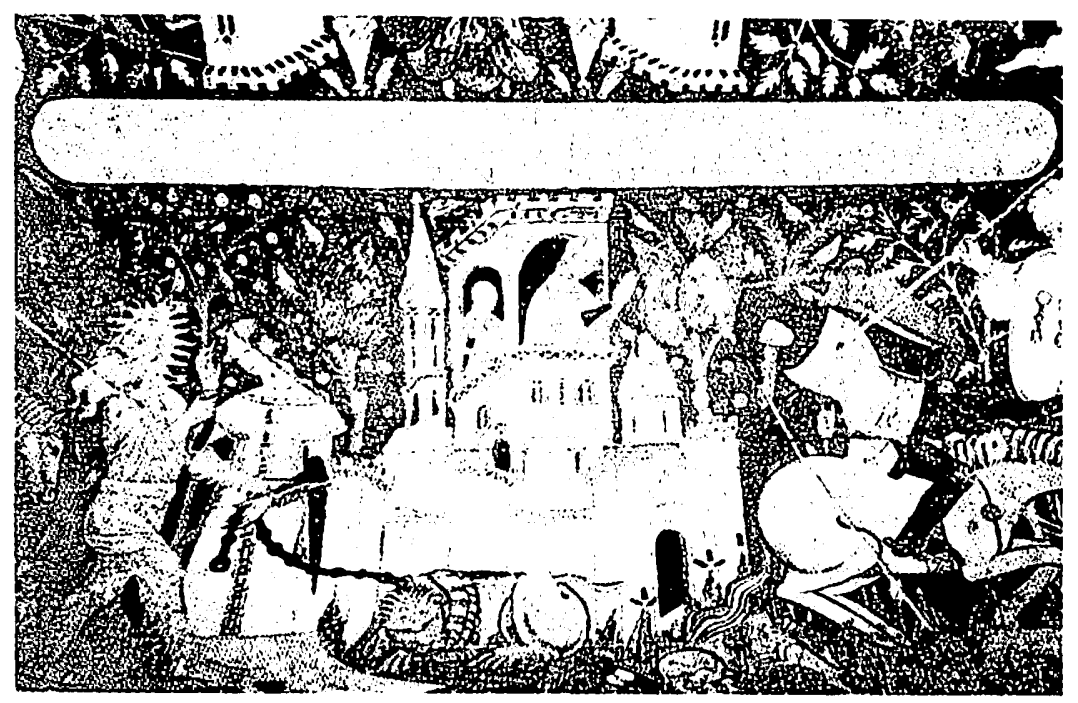

Alhambra. Sala de ha Justivias. Detalle.

neos entre moros y cristianos; jardines paradisíacos; escenas de caza y otros temas exóticos, que en gran medida nos recuerdan pasajes de la Crónica del Condestable ya comentados y que, como también ha interpretado Bermúdez Pareja, "parecen secuencias o momentos sucesivos de la misma acción, desarrollada en el ambiente mudejarizante y de íntimas relaciones sociales entre moros y cristianos de la frontera de Granada". (10).

Pese a que la técnica de construcción de las bóvedas, una estructura de madera recubierta internamente con cuero fijado a las vigas por clavos y cuñas de bambú, es granadina, las pinturas estilísticamente responden al gusto del gótico internacional fechables en el último tercio del 
siglo XIV: para unos de cierta filiación italiana y para otros incluso de mano morisca (11). Lo cual, de una forma u otra, pone de manifiesto el arraigo de un ambiente considerado tradicionalmente hostil a las imágenes (algo por lo demás históricamente discutible) el arraigo de éstas, sin duda por influjo de los cristianos fronterizos. Por fortuna, contamos con el testimonio del historiador Ibn Jaldun, testigo excepcional en la corte de Muhammad V en Granada, cuando nos refiere como se había adoptado entre los andalusíes la costumbre de decorar sus casas y palacios con figuras humanas por contaminación de sus vecinos cristianos (12).

Un último detalle presente en estas pinturas, que va a tener amplia resonancia en toda la decoración de la Alhambra. es la presencia de

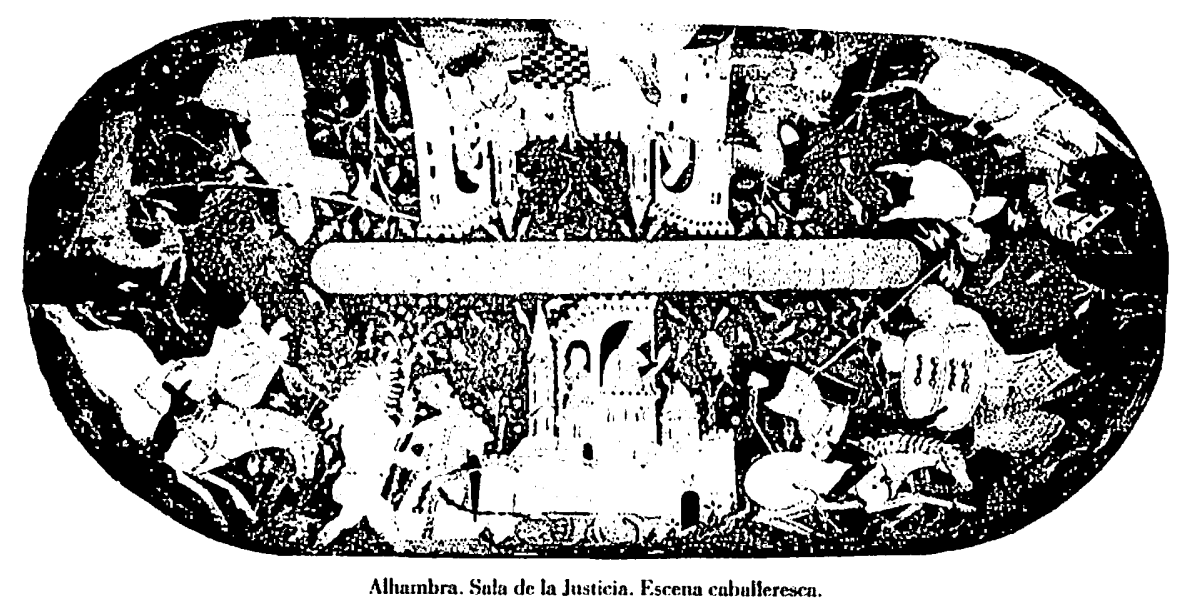

ese escudo de factura castellana recorrido por una banda en diagonal en la escena de los mandatarios o Reyes, y que es, ni más ni menos, que la "Empresa" o Divisa dada por Fernando III a Aben Alhamar, el fundador de la dinastía nazarí, y que como tal emblema identifica a la Casa y en consecuencia se repite infinidad de veces entre los alicatados y yeserías por todas las estancias de los Palacios: unas veces con la banda lisa y otras recorrida con la leyenda arábiga. Curiosa y significativa prueba de la influencia o aceptación de gustos y usos caballerescos cristianos en la corte granadina.

Al otro lado del Mediterráneo, el . Norte de Africa, frontero al reino nazarí, representaba una vecindad muy distinta. Bajo el dominio de los meriníes, con capital en Fez., las relaciones con Granada no sólo no eran 
de confrontación sino, al contrario, amistosas y donde los intercambios culturales, recíprocos, ayudaron a mantener en lo artístico aquella "koiné" que los almohades intentaron por última vez entre el Magreb y Al Andalus a finales del siglo XII, que me parece bien definida por esa arquitectura que H. Terrasse denominó "hispanomusulmana".

Por medio de los meriníes se adoptaron formas y tipos arquitectónicos de Oriente Medio como la medersa o madrasa, de tan felices resultados en Fez, y su presencia inmediata en el ámbito granadino (G. Marçais ha llegarlo afirmar que el Patio de los Leones de la Ahambra no puede entenderse sin el desarrollo de este tipo en el Norte de Africa), para a su vez aquella parte del Magreb recibir inlluencias nazaries. $\Lambda$ sí, el citado Terrasse vio.

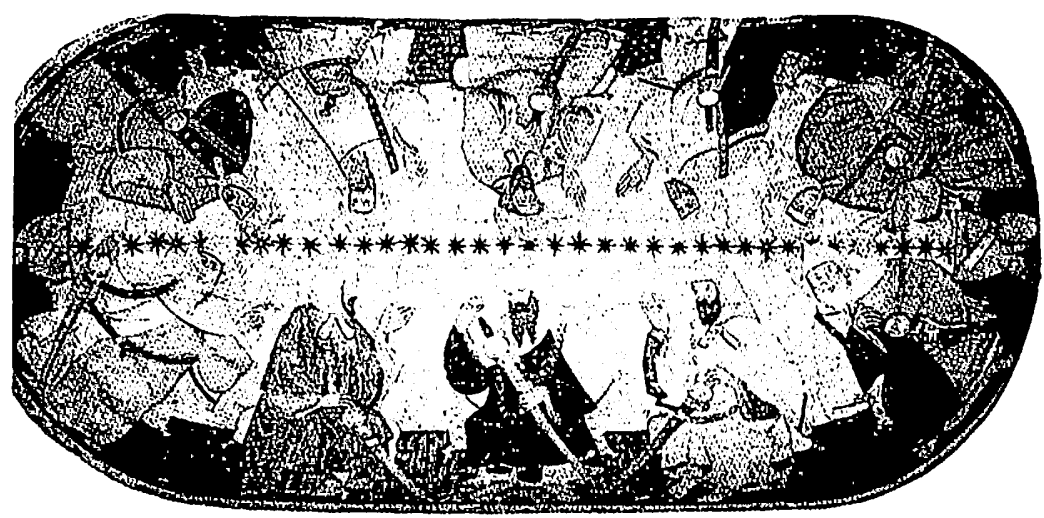

Alhambra. Sula de la Justiria. Reunión de notabless (?).

por ejemplo, en las casas defendidas por torre existentes en la aldea de Bullones, próxima a Ceuta, una derivación de la casa de campo de la Vega de Granada, trasunto a su vez de la casa con mirador que podemos ver en el Partal (Alhambra) (13), aludida más arriba. También en Bullones, en el interior de alguna casa han aparecido zócalos pintados de almagre en sintonía con los que hoy vemos en el retrete de Comares y en otros puntos de la Alhambra; al igual que un zócalo de alicatado del Museo Arqueológico de Cádiz procedente de Ceuta es de raigambre nazarí, o la abundante cerámica con motivos zoomorfos aparecida asimismo en el entorno ceutí (14).

Más fuerte, quizá por más tardía. puede ser la presencia andaluza en Tetuán, con influjos granadinos muy visibles en el palacio del Bajá 
Ahmad y sobre todo en las torres y elementos de fortificación, matizando en este aspecto también una influencia portuguesa, consecuencia del dominio luso a principios del siglo XV de Arcila y Ceuta (15).

En cualquier caso, la huella nazarí se hace más ostensible a raíz de la toma de Granada por los Reyes Católicos, fruto de una considerable masa migratoria que se asentaría en los dominios meriníes. Tetuán sería un caso de los mejor documentados, pero también Fez vio en pleno siglo XVI cómo en la misma mezquita al-Qarawiyyin surgían en su sahn dos pabellones similares a los del Patio de los Leones. O cómo la fabulosa medersa Bu? Inaniyya se revestía de una decoración que diríamos alhambreña. Pero en estos casos tan evidentes hay que hacer notar la observación de O. Crabar en el sentido de que se trata más de un efecto externo que de una profunda asunción del concepto espacial, distinto a uno y otro lado del mar.

En resumen, frente a la fácil y se supone, "natural", expansión del arte nazarí por el Norte de Africa, su penetración en la Frontera cristiana de la península es más compleja y en cierto modo más profunda, en la medida que la Granada musulmana también fue alcanzada por la cultura cristiana en ese largo proceso de ósmosis que fue la historia medieval en España a través del filtro fronterizo. 
1. CARRIAZO ARroOl:a, J. de Mala.: lin le firontera de Ciranada. Sevilla. 1971.

2. Idem. Introducción. p. VIII.

3. I.ADERO QLESAD.A. M. A.: "Ensayn solore la historia social de Andalucía eu la Baja lidacl Media y los motivos del predominio ariscuerático". Lin Actas / Coloquio Historia de Andalucia. Andalucía medieral, Córdoba. 1082. Pp. $219-2+4$.

4. Hechos del Condestuble Don Miguel Lueres de lormeo, Fisl. a cargo de Juan de Mala CARRIAZO. Madrid, 19+0. lista edición subsama low errores de la primera. publicada hacia 185is. por Pascual de Bayangos. Mhoral se anuncia una uneva a careco de la Exema. Diputiación de Jaćn.

5. ldem. p. + ? 1 .

6. Lia presencia del moro poll las Fiestis ilel

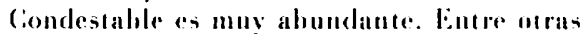
podría destacarse, además de la cinada de los moriscos devorados por un dragón. la que launhién uvo por escenario la firene de la Magdalrna el Domingo segundo día de Pascua, cuando "desetentos cahalleros... me ubitu morisen e los otros cristianos" hicieron justas que acabarmon con la derrota de los moros tirando al pilar de la fuente (bautismo simbólico) al Profera Mahomil. porque aquelles "...Fingieron venir con su rey dre Marruecos de su revino, y trayan delante al sil profeca Mahemad. de la casa ile Mera..." lelem. III. 99-100.

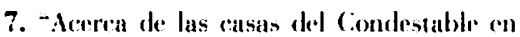
laćn". Apéndice a La Crónica ded Condessuble
Irrenzo, ecl. de P. de Ginymugs. Hemorial Mistórico espoñol T'. VIII. Maudrid. 1855. Bsir Apéndice fur reproducido en la Revisa Don Lope de Sosa tño III: .ím. 31: 191:. pp. 207-210.

8.- M.WV. Catrilogo Mommental de la cinderd de Jaén y su Término Jaén 1985, p. 1. 7-50).

9. Fur Leopoldo TORRES BNI.BAS quien dudo del carácter de reges que pudieran tener cstas pinturas. (Ars Ilispamiae. T. NV. p. 120).

10. BERMLDI:\% PARR:1A. J.: Pinturas sobre

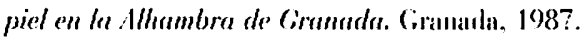
p. 30 .

11. Vintre los primeros destara. Manuel GONI:\% MORE:NO (Ginio de Granadu (iranada.

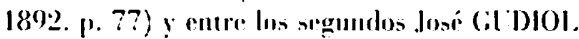
RICAR'T Mrs Mispomion 'T. IX. Maddrid. 195.j. p. +8$)$.

12. Vidl. TORRLS B.IIBAS. L.: op. rit.. p. 191.

13. T1:RRASS1:. II.: "Ouelques remarques sur les cidifieres de Brolyumes". Al-Amblehes. I.II. pr. $213-221$.

14. POSAC: MON C:. "Cerámica ron decoración zomomorfa hallada coll Ceuta". lin tali III Congreso di studi Arubi o Istamici . Nápoles. 196 ? pp. $.50 .5-507$.

15. PAVON MAIDONADO. Basiliu. "Arto hispanu-musulmán "un Cicuta y Truán" Cuadernos de la Alhambra . 1úm. 6. Granula. 1970. pp. (6)-107. Fundamental para esta zona. En parricular solure Telusin! sus fortifirariones. pp. $8010-104$. 